\title{
Application of the COOP/WONCA charts to aged patients with chronic obstructive pulmonary disease: a comparison between Japanese and Chinese populations
}

Midori Yamaguchi ${ }^{1}$, Motoyuki Nakao ${ }^{1}$, Hideto Obata ${ }^{2}$, Hideki Ikeda ${ }^{3}$, Tetsuro Kanda ${ }^{3}$, Qiao Wang ${ }^{4}$, Yoriko Hara ${ }^{1}$, Hisamitsu Omori ${ }^{5}$ and Yoko Ishihara ${ }^{1^{*}}$

\begin{abstract}
Background: The prevalence of chronic obstructive pulmonary disease (COPD) is similar in Japan and China and is increasing due to high rates of smoking in these countries. Reducing COPD is an important public health issue. The goals of this study were to verify the reliability and validity of the Japanese version of the COOP/WONCA charts, a tool for measuring health status, and to examine the qualitative differences in health status between Japanese and Chinese patients with COPD and between these patients and healthy subjects.
\end{abstract}

Methods: From 2008 to 2011, we examined the factors affecting the health status of Japanese and Chinese populations living in six cities. Participants were patients with COPD staged according to the Global Initiative for Chronic Obstructive Lung Disease (GOLD) criteria (140 Japanese, 201 Chinese) and healthy subjects (243 Japanese, 199 Chinese), all 50 to 79 years old. Health status was measured by using the COOP/WONCA charts, and basic information such as smoking status and medical history was reported by the participants.

Results: The Japanese and Chinese versions of the COOP/WONCA charts were shown to be reliable and valid by test-retest, comparison with the SF-36 and respiratory symptoms, and correlation of results obtained from patients and their physicians. Stepwise multiple regression analyses demonstrated that "Physical fitness", "Daily activities", and "Social activities" were predicted by COPD status and/or respiratory symptoms; "Feelings" by nationality and respiratory symptoms; "Pain" by sex and respiratory symptoms; and "Overall health" by nationality. When the COOP/ WONCA scores were stratified by nationality, age, sex, and COPD status, the difference of each score between the patients and healthy subjects was larger for the Chinese subjects than for the Japanese. The physical, psychosocial activities, and pain scores increased significantly as COPD status worsened in Chinese subjects, whereas these scores were not affected by sex, age, or COPD status for Japanese subjects. Brinkman index and use of smoky fuel indoors affected the COOP/WONCA scores in Chinese patients but not in Japanese patients.

Conclusions: The Japanese COOPNONCA charts are reliable and valid. COPD more severely affected the health status of Chinese participants than of Japanese participants. These results suggest that countermeasures against insufficient health care and smoky environments may improve the health status of Chinese patients with COPD.

Keywords: COOP/WONCA chart, SF-36, Chronic pulmonary diseases, Health status, Asians, Japanese, Chinese

\footnotetext{
* Correspondence: blackcat@med.kurume-u.ac.jp

${ }^{1}$ Department of Public Health, School of Medicine, Kurume University,

Kurume, Fukuoka 830-0011, Japan

Full list of author information is available at the end of the article
} 


\section{Background}

Chronic obstructive pulmonary disease (COPD) is the fourth leading cause of death in the world. The main risk factors for COPD are cigarette smoking [1] and aging [2], and its prevalence and related mortality are expected to increase as the population ages [3]. Therefore, development of a strategy to prevent and treat COPD is an urgent issue in public health. Because the increased numbers of COPD patients represent an economic and social burden [4], there is a need for countermeasures in Asia where the air pollution is severe [5], the population is aging rapidly, and smoking rates are high.

Smoking rates are higher in Asia than in the Western developed countries. The smoking rate in Japan is $23.4 \%$ (38.2\% for men and $10.9 \%$ for women) [6], although it has declined rapidly in response to a governmental campaign [7]. According to the World Health Organization [6], the smoking rate in China is $26.1 \%$ (52.1\% for men and $2.3 \%$ for women). Similarly, a study of the general population of China aged 15 years and older reported the smoking rate to be $27.7 \%$ (52.1\% for men and $2.3 \%$ for women) [8]. The prevalence of COPD is $10.9 \%$ (16.4\% for men and 5.0\% for women) in Japan [9] and $8.2 \%$ (12.4\% for men and $5.1 \%$ for women) in China [10]. Another study reported a prevalence of $9.3 \%$ for men and $5.1 \%$ for women among 602 subjects from the general population of Guangzhou, China [11].

The smoking rate is currently decreasing in Japan, whereas in China the smoking rate is increasing. The prevalence of COPD and mortality from the disease are expected to increase due to prolonged life expectancy. The economic burden of treatment for COPD [12] and the social burden of the loss of disability-adjusted life years due to COPD [13] are also increasing because the prevalence of COPD, which is a slowly progressive chronic disease and puts patients at increased risk of infectious disease [14], is greatly elevated in those who are 40 years or older. However, little is known about the health status of older patients with COPD in Asia, and no study has compared the health status of Japanese and Chinese populations, who live with completely different medical systems, environments, and other patient circumstances.

International comparative studies using questionnaires must consider the cultural background of participants, such as language and customs. In addition, for research targeting a geriatric subject, a simplified questionnaire is required that is written in short, easy-to-understand sentences; is visually apparent; and can be completed in a short time. The COOP/WONCA charts, which consist of seven simple questions with associated drawings, were developed by the World Organization of National Colleges, Academies and Academic Associations of General
Practitioners/Family Physicians (WONCA) to assess the health status of patients visiting primary care physicians. The reliability and validity of the English [15] and Chinese [16] versions have been verified. However, the Japanese version of the COOP/WONCA charts has been examined only for schoolchildren and not for adults [17-19]. Only a few studies have examined the health status of patients with COPD by using the COOP/WONCA charts in Western countries and China, and few studies have evaluated the health status of older patients with COPD, although one international comparative study has used the COOP/ WONCA charts [20]. Therefore, we performed this study to verify the reliability and validity of the Japanese version of the COOP/WONCA charts and to examine the qualitative differences of health status between Japanese and Chinese patients with COPD ages 50-79 years and between these patients and healthy subjects.

\section{Methods}

\section{Subjects}

The survey was conducted in six cities in Japan and China from 2008 to 2011. The sites are Shimonoseki-shi (Yamaguchi prefecture), Goto-shi (Nagasaki prefecture), and Kumamoto-shi (Kumamoto prefecture) in southwestern Japan and Beijing, Shanghai, and Ulanhot (Inner Mongolia) in China. Patients ages 50-79 years visiting outpatient clinics and healthy subjects having medical checkups at health care centers were enrolled. This study was approved in advance by the Clinical Ethics Committee of Kurume University, Fukuoka, Japan. The objectives and other details of the study were explained to the subjects, and their written informed consent was obtained.

Pulmonologists examined the pulmonary function of the patients with COPD in hospitals or clinics, diagnosed respiratory disease, and determined COPD stage (I, II, III, or IV) using the Global Initiative for Chronic Obstructive Lung Disease (GOLD) criteria [21]. Patients with home oxygen therapy were excluded. Pulmonary function of healthy subjects was tested in health care centers. Healthy subjects did not have dyslipidemia or respiratory, circulatory, gastrointestinal, or endocrine disease.

The questionnaire is a self-administered booklet that consists of requests for basic information, four questions related to respiratory symptoms ("cough caused by the weather", "sputum without infectious disease", "sputum in the morning", and "wheezing"), and the COOP/ WONCA charts. Medical staff distributed and collected the questionnaires at the hospitals and clinics. Health care centers mailed the questionnaires to healthy participants beforehand and collected them at health checkups. Permission to use the Japanese version of SF-36v2 (SF-36) Additional file 1 was obtained from Quality Metric (New 
York, NY, USA). For the Japanese and Chinese versions of the COOP/WONCA charts Additional file 2, permission was obtained from the Japan Primary Care Association and Dr. Cindy Lam, who developed the Chinese version of the COOP/WONCA charts. The responses to the COOP/ WONCA charts are scored on a five-point ordinal scale ranging from 1 to 5 ( 1 = best, 5 = worst). The responses to the SF-36 are on three-, five-, or six-point ordinal scales, from which we calculated the eight subscales from 0 to 100 points $(\max =100)$ as instructed in the manual [22].

\section{Analytical methods}

All completed questionnaires were assigned identification numbers after collection. All cases missing values in the questionnaire were removed from the data set before the statistical analyses were performed. Data were analyzed by $t$-test, chi-square test, correlation analysis, and a multiple-regression analysis by using JMP Ver.10.0 (SAS Institute, Cary, NC, USA) and SPSS Ver.17 (IBM, Armonk, NY, USA). Probability less than 0.005 was considered to be statistically significant.

\section{Results}

\section{Characteristics of participants}

Study subjects included 140 COPD patients with GOLD status I-IV in Japan and 201 in China, as well as 243 healthy subjects in Japan and 199 in China (Table 1). The ratio of men to women was 3:2 for the Japanese and 1:1 for the Chinese group. Approximately $40 \%$ of the males of both nationalities had white-collar jobs, and approximately $27 \%$ (Japanese) and $37 \%$ (Chinese) had blue-collar jobs. Approximately 33\% of Japanese men and $20 \%$ of Chinese men were retired, as was expected because this study was targeted to older individuals. The proportion of housewives was high among both population groups. In addition, Chinese women were more likely to have blue-collar jobs than were Japanese women.

COPD status was determined in accordance with the GOLD criteria. Among male participants, $42.2 \%$ of Japanese and $62.5 \%$ of Chinese were patients with COPD; among female participants, $28.1 \%$ of Japanese and $37.0 \%$ of Chinese were patients with COPD (Table 1). The percentages of current and ex-smokers among healthy subjects was $78.2 \%$ of Japanese men, $39.7 \%$ of Chinese men, $12.7 \%$ of Japanese women, and $2.5 \%$ of Chinese women. Among the healthy subjects, more Japanese than Chinese were current or ex-smokers, regardless of sex. A higher proportion of Japanese than of Chinese male patients had both smoking experience and COPD; however, the proportion of female COPD patients with smoking experience was higher in the Chinese than in the Japanese. A higher percentage of patients with COPD than of healthy subjects had a Brinkman Index (BI; number of cigarettes smoked per day times smoking years) greater than 500. All
Japanese participants used gas or electricity for cooking and heating, whereas $21 \%-25 \%$ of Chinese participants used fuel that causes indoor air pollution, such as coal, which was the most common heating source. Some participants in Ulanhot, Inner Mongolia, used wood, the dried dung of sheep, or dried corncobs as heating sources.

\section{The reliability and validity of the Japanese and Chinese versions of the COOP/WONCA charts}

We examined the correlation between COOP/WONCA chart scores and SF-36 subscale scores in matched subjects (same sex and age). For participants of both nationalities, the "Physical fitness", "Social activities", "Overall health", and "Pain" COOP/WONCA charts were highly correlated with the SF-36 subscales "Physical functioning", "Role emotional", "General health perceptions", and "Bodily pain," respectively (Table 2). The "Feelings" and "Daily activities" COOP/WONCA chart items correlated with different subscales of SF-36, depending on nationality. In the Japanese group, the COOP/WONCA scores of "Feelings" and "Daily activities" were correlated with the scores of "Mental health" and "Vitality" of the SF-36 subscales. In contrast, in the Chinese group, the COOP/ WONCA scores of "Feelings" and "Daily activities" showed the highest correlation with "General health perceptions" and "Bodily pain" of the SF-36 subscales. In both groups, the correlations between the COOP/ WONCA charts and the related subscales of the SF-36 were relatively high except for "Change in health". Testretest reliability was examined with 104 Japanese and 22 Chinese participants, with a one-month interval between tests. The intraclass correlation coefficients (ICC) ranged from 0.696 to 0.890 in the Japanese subjects and from 0.657 to 0.817 in the Chinese subjects, except for "Change in health" (data not shown), demonstrating that both the Japanese and Chinese versions of the COOP/ WONCA charts had excellent reliability.

Next, to assess the external validity of the COOP/ WONCA chart, we examined the correlation of COOP/ WONCA chart scores between Japanese and Chinese patients with COPD and their physicians, matched with age, sex, and COPD status. The scores for all of the items, except for "Pain" in the Japanese group, were highly correlated between the physicians and the patients (Table 3). For both nationalities, the scores assigned by the physicians were higher (worse) than those assigned by the patients, except for "Pain" in the Japanese group and "Daily activities" in the Chinese group. The difference of the "Pain" score between the physicians and patients was relatively large (mean, -0.46) in the Japanese population, indicating that the patients felt more severe pain than their physicians recognized.

We also examined the correlation between COOP/ WONCA chart scores and single predictive variables 
Table 1 Characteristics of participants

\begin{tabular}{|c|c|c|c|c|c|c|c|}
\hline & & Male $(\mathrm{n}$ & $=438)$ & & Female & $(n=345)$ & \\
\hline & & & & Chi-squared & & & Chi-squared \\
\hline & & Japanese & Chinese & & Japanese & Chinese & \\
\hline Population (n (\%)) & & $230(52.5)$ & $208(47.5)$ & & $153(44.3)$ & $192(55.7)$ & \\
\hline Age (y) & (mean $\pm \mathrm{SD})$ & $62.77 \pm 8.53$ & $65.84 \pm 7.69$ & & $60.10 \pm 7.62$ & $63.86 \pm 8.46$ & \\
\hline Body Mass Index & (mean $\pm \mathrm{SD})$ & $23.06 \pm 3.30$ & $23.61 \pm 3.86$ & & $22.37 \pm 3.06$ & $24.02 \pm 3.88$ & \\
\hline Job (n (\%)) & White collar & $92(51.4)$ & $87(48.6)$ & 0.0056 & $50(50.0)$ & $50(50.0)$ & 0.0245 \\
\hline & Blue collar & $63(45.3)$ & $76(54.7)$ & & $33(33.0)$ & $67(67.0)$ & \\
\hline & Housewife & $0(-)$ & $0(-)$ & & $70(48.3)$ & $75(51.7)$ & \\
\hline & Retired & $75(64.1)$ & $42(35.9)$ & & $0(-)$ & $0(-)$ & \\
\hline & Missing & $0(0.0)$ & $3(100.0)$ & & $0(-)$ & $0(-)$ & \\
\hline Group (n (\%)) & Healthy & $133(63.0)$ & $78(37.0)$ & $<0.0001$ & $110(47.6)$ & $121(52.4)$ & 0.0817 \\
\hline & COPD & $97(42.7)$ & $130(57.3)$ & & $43(37.7)$ & $71(62.3)$ & \\
\hline Cigarette smoking (n (\%)) & Healthy subjects & & & & & & \\
\hline & Current smoker & $43(66.2)$ & $22(33.8)$ & $<0.0001$ & $9(75.0)$ & $3(25.0)$ & 0.0045 \\
\hline & Ex-smoker & $61(87.1)$ & $9(12.9)$ & & $5(100.0)$ & $0(0.0)$ & \\
\hline & Non smoker & $29(43.3)$ & $38(56.7)$ & & $96(45.7)$ & $114(54.3)$ & \\
\hline & Missing & $0(0.0)$ & $9(100.0)$ & & $0(0.0)$ & $4(100.0)$ & \\
\hline & COPD patients & & & & & & \\
\hline & Current smoker & $13(28.3)$ & $33(71.7)$ & 0.0007 & $2(25.0)$ & $6(75.0)$ & 0.0041 \\
\hline & Ex-smoker & $67(52.3)$ & $61(47.7)$ & & $6(22.2)$ & $21(77.8)$ & \\
\hline & Non smoker & $17(40.5)$ & $25(59.5)$ & & $35(50.0)$ & $35(50.0)$ & \\
\hline & Missing & $0(0.0)$ & $11(100.0)$ & & $0(0.0)$ & $9(100.0)$ & \\
\hline Brinkman Index (n (\%)) & Healthy subjects & & & & & & \\
\hline & 0 & $29(43.3)$ & $38(56.7)$ & $<0.0001$ & $96(45.7)$ & $114(54.3)$ & 0.0064 \\
\hline & $0<\mathrm{Bl} 500$ & $44(64.7)$ & $24(35.3)$ & & $13(81.3)$ & $3(18.8)$ & \\
\hline & $\mathrm{BI}>500$ & 60 (89.6) & $7(10.4)$ & & $1(100.0)$ & $0(0.0)$ & \\
\hline & Missing & $0(0.0)$ & $9(100.0)$ & & $0(0.0)$ & $4(100.0)$ & \\
\hline & COPD patients & & & & & & \\
\hline & 0 & $17(40.5)$ & $25(59.5)$ & $<0.0001$ & $35(50.0)$ & $35(50.0)$ & 0.0036 \\
\hline & $0<\mathrm{B} \mid 500$ & $17(27.9)$ & $44(72.1)$ & & $4(28.6)$ & $10(71.4)$ & \\
\hline & $\mathrm{Bl}>500$ & $63(55.8)$ & $50(44.2)$ & & $4(19.0)$ & $17(81.0)$ & \\
\hline & Missing & $0(0.0)$ & $11(100.0)$ & & $0(0.0)$ & $9(100.0)$ & \\
\hline Heating sources (n (\%)) & Biomass, Coal, Animal dung & $0(0.0)$ & $52(100.0)$ & $<0.0001$ & $0(0.0)$ & $41(100.0)$ & $<0.0001$ \\
\hline & Gas, Electric, Steam & $230(60.1)$ & $153(39.9)$ & & $153(50.7)$ & $149(49.3)$ & \\
\hline & Missing & $0(0.0)$ & $3(100.0)$ & & $0(0.0)$ & $2(100.0)$ & \\
\hline
\end{tabular}

(age, sex, body mass index, BI, heating sources, the number of respiratory symptoms, and COPD status). For the Japanese group, "Physical fitness", "Feelings", and "Social activities" were highly correlated with age, and five items ("Physical fitness", "Feelings", "Social activities", "Change in health", and "Overall health") were correlated with the number of respiratory symptoms and COPD status (Table 4, upper panel). For the Chinese group, "Physical fitness" and "Overall health" were correlated with age, the rest of the scores except for "Change in health" were correlated with both $\mathrm{BI}$ and the number of respiratory symptoms, and all scores were highly correlated with COPD status (Table 4, lower panel). Moreover, "Daily activities" and "Social activities" were correlated significantly with heating sources.

\section{Stepwise multiple regression analyses to determine the} predictive variables affecting each item of the health status To determine which variables predict the COOP/ WONCA chart scores, we performed stepwise multiple 
Table 2 Correlation between the COOP/WONCA charts and SF-36 subscales in age and sex matched Japanese and Chinese subjects

\begin{tabular}{|c|c|c|c|c|c|c|c|}
\hline \multirow[t]{2}{*}{ Japanese $(n=26)$} & \multicolumn{7}{|c|}{ COOP/WONCA chart } \\
\hline & Physical fitness & Feelings & Daily activities & Social activities & Change in health & Overall health & Pain \\
\hline \multicolumn{8}{|l|}{ SF-36 subscale } \\
\hline Physical functioning & -0.508 & -0.180 & -0.344 & -0.505 & -0.312 & -0.151 & -0.424 \\
\hline Role physical & -0.368 & -0.046 & -0.262 & -0.569 & -0.031 & -0.288 & -0.237 \\
\hline Bodily pain & -0.176 & -0.141 & -0.184 & -0.074 & -0.287 & -0.278 & -0.797 \\
\hline General health perceptions & -0.196 & -0.235 & -0.367 & -0.497 & -0.022 & -0.472 & -0.266 \\
\hline Vitality & -0.360 & -0.608 & -0.632 & -0.510 & -0.102 & -0.241 & -0.441 \\
\hline Social functioning & -0.492 & -0.484 & -0.597 & -0.668 & -0.000 & -0.397 & -0.238 \\
\hline Role emotional & -0.392 & -0.191 & -0.332 & -0.688 & -0.159 & -0.263 & -0.258 \\
\hline Mental health & -0.304 & -0.674 & -0.454 & -0.545 & -0.192 & -0.238 & -0.465 \\
\hline \multirow[t]{2}{*}{ Chinese $(n=26)$} & \multicolumn{7}{|c|}{ COOP/WONCA chart } \\
\hline & Physical fitness & Feelings & Daily activities & Social activities & Change in health & Overall health & Pain \\
\hline \multicolumn{8}{|l|}{ SF-36 subscale } \\
\hline Physical functioning & -0.847 & -0.872 & -0.793 & -0.758 & -0.097 & -0.676 & -0.866 \\
\hline Role physical & -0.695 & -0.831 & -0.789 & -0.780 & -0.316 & -0.675 & -0.883 \\
\hline Bodily pain & -0.617 & -0.875 & -0.882 & -0.843 & -0.456 & -0.656 & -0.905 \\
\hline General health perceptions & -0.773 & -0.912 & -0.876 & -0.848 & -0.283 & -0.720 & -0.899 \\
\hline Vitality & -0.528 & -0.735 & -0.605 & -0.632 & -0.014 & -0.537 & -0.745 \\
\hline Social functioning & -0.469 & -0.741 & -0.739 & -0.759 & -0.333 & -0.487 & -0.726 \\
\hline Role emotional & -0.654 & -0.826 & -0.859 & -0.869 & -0.449 & -0.712 & -0.903 \\
\hline Mental health & -0.414 & -0.673 & -0.591 & -0.638 & -0.170 & -0.428 & -0.672 \\
\hline
\end{tabular}

Data are presented as Pearson's correlation coefficients.

regression analyses with the scores of each COOP/ WONCA chart item as dependent variables and population group, sex, age, COPD status, the number of respiratory symptoms, BI, and heating sources as predictive variables. The variance inflation factors were 2 or less, and the all F-values resulting from the analyses of variance were significant at $P<0.0001$. The predictive variables with standardized partial regression coefficients $>0.2$ were COPD status for "Physical fitness" and "Daily activities", COPD status and the number of respiratory symptoms for "Social activities", nationality and the number of respiratory symptoms for "Feelings", sex and the number of respiratory symptoms for "Pain", nationality for "Overall health", and heating sources for "Change in health" (Table 5).

\section{Comparison of health status between groups (nationality, sex, age, COPD status)}

Using the results obtained from the stepwise multiple regression analyses; we compared the COOP/WONCA chart scores between the groups stratified by nationality, sex, age, and COPD status (moderate, severe). Differences in the scores between healthy subjects and patients with COPD were small in the Japanese group; health status was not affected by sex, age, or COPD status except for the group of the patients with moderate
COPD aged 70-79 years (Table 6, upper panel). In contrast, in the Chinese group, differences were large between healthy subjects and patients with COPD, and the scores of all items except for "Change in health" tended to worsen in association with the progression of COPD in the Chinese group. There were no effects of sex or age between healthy subjects and the patients with moderate or severe COPD. Although a few scores were worse in older subjects and differed between the sexes, these results did not show any pattern.

\section{Discussion}

Validity and reliability of the Japanese and Chinese versions of COOP/WONCA charts

The Chinese version of the COOP/WONCA charts [16] had already been shown to be reliable and valid for nervous system diseases, orthopedic disease, cancer, and strokes in China. Patients' acceptance of the test is high, and the test is useful for the doctors who are evaluating them [16,23]. Although the Japanese version of the COOP/WONCA charts has been used to measure quality of life in the field of ophthalmology [24], and as a health survey and to measure quality of life in pediatrics $[25,26]$, its reliability and validity have not been fully confirmed in an adult Japanese population. In our study, we enrolled 
Table 3 Correlation of COOP/WONCA chart scores assigned by the patients and their physicians in age and sex matched Japanese and Chinese patients with COPD

\begin{tabular}{lccc}
\hline & $\begin{array}{c}\text { Pearson's } \\
\text { correlation } \\
\text { coefficient }\end{array}$ & $\begin{array}{c}\text { Physician's } \\
\text { score }\end{array}$ & $\begin{array}{c}\text { Patient's } \\
\text { score }\end{array}$ \\
\hline Japanese $(\mathrm{n}=13)$ & 0.801 & $4.23 \pm 0.73$ & $4.00 \pm 1.29$ \\
Physical fitness & 0.617 & $1.85 \pm 0.80$ & $1.54 \pm 0.52$ \\
Feelings & 0.722 & $2.15 \pm 0.99$ & $1.92 \pm 0.95$ \\
Daily activities & 0.527 & $1.23 \pm 0.44$ & $1.08 \pm 0.28$ \\
Social activities & 0.815 & $3.15 \pm 0.38$ & $3.00 \pm 0.82$ \\
Change in health & 0.850 & $3.00 \pm 0.71$ & $2.77 \pm 0.83$ \\
Overall health & 0.237 & $1.46 \pm 0.78$ & $1.92 \pm 1.12$ \\
Pain & & & \\
Chinese (n = 13) & 0.965 & $3.85 \pm 0.90$ & $3.77 \pm 1.01$ \\
Physical fitness & 0.941 & $2.00 \pm 0.82$ & $1.92 \pm 0.76$ \\
Feelings & 0.974 & $2.54 \pm 1.20$ & $2.62 \pm 1.12$ \\
Daily activities & 0.953 & $2.00 \pm 0.91$ & $1.92 \pm 0.86$ \\
Social activities & 0.980 & $3.31 \pm 1.38$ & $3.23 \pm 1.30$ \\
Change in health & 0.826 & $3.92 \pm 0.95$ & $3.77 \pm 0.93$ \\
Overall health & 0.978 & $2.38 \pm 1.26$ & $2.31 \pm 1.32$ \\
Pain & &
\end{tabular}

Data in scores and differences are presented as mean \pm SD. subjects ages 50-79 years because the target of this study was patients with COPD, and the incidence of COPD increases with age. We verified the reliability and validity of the COOP/WONCA chart in Japanese and Chinese groups of healthy subjects and patients with COPD.

The "Feelings" and "Daily activities" COOP/WONCA charts showed high correlation with the mental component scores of the SF-36 in the Japanese population and the physical component scores of the SF-36 in the Chinese population. "Change in health", which asks about changes in health status compared with that of the previous two weeks, was correlated with the physical component of SF-36 in both groups, but most with "physical functioning" in the Japanese group and most with "bodily pain" in the Chinese group. Other than these differences, the correlation of the COOP/WONCA charts and the subscales of SF-36 were consistent between the Japanese and Chinese groups. These results suggest that the Japanese and Chinese versions of the COOP/WONCA charts are appropriate for evaluating the health status of older healthy subjects and patients with COPD. The reproducibility of the COOP/WONCA charts, except for "Change in health", was confirmed: in the test-retest, the ICC of each item was in the range of 0.657 to 0.890 in both the Japanese and Chinese populations.

We evaluated external validity and sensitivity by correlating the patient's evaluation with their doctor's evaluation using the same COOP/WONCA charts, the number of respiratory symptoms associated with COPD, and the COPD status. After the subjects were matched

Table 4 Spearman's rank correlation coefficient between COOP/WONCA chart scores and subjects' parameters

\begin{tabular}{|c|c|c|c|c|c|c|c|}
\hline \multirow[b]{2}{*}{ Japanese $(n=370)$} & \multicolumn{7}{|c|}{ COOP/WONCA chart } \\
\hline & Physical fitness & Feelings & Daily activities & Social activities & Change in health & Overall health & Pain \\
\hline Age & $0.244^{* *}$ & $-0.175^{*}$ & 0.021 & $-0.203^{* *}$ & -0.120 & -0.043 & -0.108 \\
\hline Sex & 0.093 & 0.065 & -0.045 & 0.029 & -0.089 & -0.101 & $0.173^{*}$ \\
\hline Body Mass Index & 0.007 & -0.007 & -0.064 & -0.023 & -0.026 & -0.084 & 0.003 \\
\hline Brinkman index & -0.031 & -0.036 & 0.030 & -0.057 & 0.015 & 0.141 & -0.112 \\
\hline Heating sources & - & - & - & - & - & - & - \\
\hline Number of respiratory symptoms & $0.175^{*}$ & -0.010 & 0.095 & -0.009 & -0.047 & $0.105^{*}$ & 0.089 \\
\hline \multirow[t]{2}{*}{ COPD status } & $0.213^{* *}$ & $-0.202^{* *}$ & 0.011 & $-0.191^{* *}$ & $-0.148^{*}$ & 0.018 & -0.037 \\
\hline & \multicolumn{7}{|c|}{ COOP/WONCA chart } \\
\hline Chinese $(n=400)$ & Physical fitness & Feelings & Daily activities & Social activities & Change in health & Overall health & Pain \\
\hline Age & $0.228^{* *}$ & 0.069 & 0.066 & 0.104 & 0.073 & $0.174^{*}$ & 0.088 \\
\hline Sex & -0.009 & -0.020 & -0.091 & -0.106 & 0.026 & -0.036 & 0.088 \\
\hline Body Mass Index & -0.070 & -0.034 & -0.086 & -0.055 & 0.041 & -0.130 & -0.041 \\
\hline Brinkman index & $0.257^{* *}$ & $0.308^{* *}$ & $0.396^{* *}$ & $0.328^{* *}$ & -0.030 & $0.253^{* *}$ & $0.206^{* *}$ \\
\hline Heating sources & 0.009 & 0.100 & $0.157^{*}$ & $0.146^{*}$ & -0.132 & 0.023 & 0.139 \\
\hline Number of respiratory symptoms & $0.368^{* *}$ & $0.547^{* *}$ & $0.653^{* *}$ & $0.616^{* *}$ & 0.098 & $0.398^{* *}$ & $0.407^{* *}$ \\
\hline COPD status & $0.452^{* *}$ & $0.575^{* *}$ & $0.738^{* *}$ & $0.681^{* *}$ & $0.200^{* *}$ & $0.484^{* *}$ & $0.429^{* *}$ \\
\hline
\end{tabular}

*: $P<0.005,{ }^{*}: P<0.001$ 
Table 5 Multiple-regression analyses of COOP/WONCA chart scores (dependent variables) and predictive variables

\begin{tabular}{|c|c|c|c|c|}
\hline \multirow[t]{2}{*}{ Dependent variables } & \multirow[t]{2}{*}{ Predictive variables } & \multirow[t]{2}{*}{$\beta$} & \multirow[t]{2}{*}{$P$} & \multirow{2}{*}{$\frac{\mathrm{R}^{2}}{\text { Adjusted } \mathrm{R}^{2}}$} \\
\hline & & & & \\
\hline \multirow[t]{6}{*}{ Physical fitness } & Population group & 0.125 & $<0.001$ & \\
\hline & Age & 0.152 & $<0.001$ & 0.245 \\
\hline & Sex & 0.132 & $<0.001$ & 0.240 \\
\hline & COPD status & 0.252 & $<0.001$ & \\
\hline & Number of respiratory symptoms & 0.161 & $<0.001$ & \\
\hline & Heating sources & & & \\
\hline \multirow[t]{6}{*}{ Feelings } & Population group & -0.280 & $<0.001$ & \\
\hline & Age & & & 0.121 \\
\hline & Sex & & & 0.119 \\
\hline & COPD status & & & \\
\hline & Number of respiratory symptoms & 0.318 & $<0.001$ & \\
\hline & Heating sources & & & \\
\hline \multirow[t]{6}{*}{ Daily activities } & Population group & & & \\
\hline & Age & 0.107 & 0.020 & 0.257 \\
\hline & Sex & & & 0.254 \\
\hline & COPD status & 0.396 & $<0.001$ & \\
\hline & Number of respiratory symptoms & 0.184 & $<0.001$ & \\
\hline & Heating sources & & & \\
\hline \multirow[t]{6}{*}{ Social activities } & Population group & & & \\
\hline & Age & -0.114 & 0.002 & 0.204 \\
\hline & Sex & & & 0.201 \\
\hline & COPD status & 0.264 & $<0.001$ & \\
\hline & Number of respiratory symptoms & 0.258 & $<0.001$ & \\
\hline & Heating sources & & & \\
\hline \multirow[t]{6}{*}{ Change of health } & Population group & 0.156 & $<0.001$ & \\
\hline & Age & & & 0.045 \\
\hline & Sex & & & 0.042 \\
\hline & COPD status & & & \\
\hline & Number of respiratory symptoms & & & \\
\hline & Heating sources & -0.204 & $<0.001$ & \\
\hline \multirow[t]{6}{*}{ Overall health } & Population group & 0.216 & $<0.001$ & \\
\hline & Age & & & 0.199 \\
\hline & Sex & & & 0.195 \\
\hline & COPD status & 0.197 & $<0.001$ & \\
\hline & Number of respiratory symptoms & 0.172 & $<0.001$ & \\
\hline & Heating sources & & & \\
\hline \multirow[t]{6}{*}{ Pain } & Population group & -0.185 & $<0.001$ & \\
\hline & Age & & & 0.117 \\
\hline & Sex & 0.207 & $<0.001$ & 0.112 \\
\hline & COPD status & 0.129 & 0.005 & \\
\hline & Number of respiratory symptoms & 0.234 & $<0.001$ & \\
\hline & Heating sources & & & \\
\hline
\end{tabular}


Table 6 Comparison of COOP/WONCA chart scores between the Japanese and Chinese groups, stratified by race, sex, age, and COPD status

\begin{tabular}{|c|c|c|c|c|c|c|c|c|c|c|}
\hline \multicolumn{2}{|l|}{ Japanese } & \multirow[b]{2}{*}{ Sex } & \multirow[b]{2}{*}{$\mathrm{n}$} & \multicolumn{7}{|c|}{ COOP/WONCA chart } \\
\hline Group & $\overline{\text { Age }(y)}$ & & & $\begin{array}{l}\text { Physical } \\
\text { fitness }\end{array}$ & Feelings & $\begin{array}{c}\text { Daily } \\
\text { activities }\end{array}$ & $\begin{array}{c}\text { Social } \\
\text { activities }\end{array}$ & $\begin{array}{l}\text { Change of } \\
\text { health }\end{array}$ & $\begin{array}{l}\text { Overall } \\
\text { health }\end{array}$ & Pain \\
\hline \multirow[t]{6}{*}{ Healthy subjects } & $50-59$ & Male & 90 & $2.12 \pm 0.92$ & $2.21 \pm 0.85$ & $1.71 \pm 0.84$ & $1.52 \pm 0.72$ & $2.97 \pm 0.32$ & $2.78 \pm 0.58$ & $2.36 \pm 0.88$ \\
\hline & & Female & 77 & $2.86 \pm 0.96$ & $2.27 \pm 0.77$ & $1.70 \pm 0.86$ & $1.52 \pm 0.58$ & $2.90 \pm 038$ & $2.69 \pm 0.65$ & $2.68 \pm 0.85$ \\
\hline & $60-69$ & Male & 35 & $2.80 \pm 1.05$ & $2.26 \pm 1.01$ & $1.77 \pm 0.97$ & $1.40 \pm 0.74$ & $2.91 \pm 0.37$ & $2.51 \pm 0.74$ & $1.94 \pm 0.80$ \\
\hline & & Female & 27 & $3.07 \pm 1.07$ & $1.96 \pm 0.85$ & $1.70 \pm 0.82$ & $1.30 \pm 0.82$ & $2.96 \pm 0.365$ & $2.78 \pm 0.70$ & $2.33 \pm 1.07$ \\
\hline & $70-79$ & Male & 8 & $3.00 \pm 1.20$ & $2.13 \pm 0.99$ & $1.75 \pm 0.71$ & $1.75 \pm 0.71$ & $3.13 \pm 0.35$ & $3.13 \pm 0.64$ & $2.50 \pm 0.53$ \\
\hline & & Female & 6 & $2.17 \pm 0.41$ & $2.50 \pm 1.52$ & $1.50 \pm 0.84$ & $1.33 \pm 0.52$ & $3.00 \pm 0.00$ & $2.17 \pm 0.75$ & $2.50 \pm 0.84$ \\
\hline \multirow{6}{*}{$\begin{array}{l}\text { Patients with } \\
\text { moderate COPD }\end{array}$} & $50-59$ & Male & 3 & $3.00 \pm 0.00$ & $2.00 \pm 0.00$ & $1.67 \pm 1.15$ & $1.00 \pm 0.00$ & $3.00 \pm 0.00$ & $3.00 \pm 1.00$ & $2.67 \pm 0.58$ \\
\hline & & Female & 4 & $2.50 \pm 0.58$ & $2.50 \pm 1.29$ & $1.50 \pm 1.00$ & $2.25 \pm 1.50$ & $3.25 \pm 0.50$ & $2.75 \pm 1.26$ & $3.25 \pm 0.50$ \\
\hline & $60-69$ & Male & 21 & $2.57 \pm 0.93$ & $1.76 \pm 0.94$ & $1.71 \pm 1.01$ & $1.38 \pm 0.86$ & $2.95 \pm 0.50$ & $2.81 \pm 0.87$ & $2.24 \pm 1.00$ \\
\hline & & Female & 15 & $2.93 \pm 1.39$ & $2.13 \pm 0.92$ & $1.87 \pm 1.13$ & $1.47 \pm 1.13$ & $2.67 \pm 0.82$ & $2.47 \pm 0.83$ & $2.40 \pm 1.18$ \\
\hline & $70-79$ & Male & 29 & $3.21 \pm 1.50$ & $1.83 \pm 0.85$ & $1.93 \pm 1.03$ & $1.17 \pm 0.47$ & $2.86 \pm 0.83$ & $2.76 \pm 0.91$ & $2.41 \pm 1.24$ \\
\hline & & Female & 17 & $2.82 \pm 1.47$ & $1.94 \pm 0.90$ & $1.41 \pm 0.71$ & $1.12 \pm 0.33$ & $2.00 \pm 1.00$ & $2.24 \pm 0.83$ & $2.82 \pm 1.13$ \\
\hline \multirow{6}{*}{$\begin{array}{l}\text { Patients with } \\
\text { severe COPD }\end{array}$} & $50-59$ & Male & 1 & 3.00 & 3.00 & 2.00 & 3.00 & 3.00 & 3.00 & 4.00 \\
\hline & & Female & 0 & - & - & - & - & - & - & - \\
\hline & $60-69$ & Male & 8 & $3.38 \pm 1.30$ & $1.13 \pm 0.35^{*}$ & $1.63 \pm 1.19$ & $1.00 \pm 0.00$ & $2.50 \pm 0.93$ & $2.63 \pm 0.92$ & $2.00 \pm 1.20$ \\
\hline & & Female & 3 & $3.00 \pm 1.00$ & $2.33 \pm 1.15$ & $2.00 \pm 1.00$ & $1.33 \pm 0.58$ & $3.33 \pm 0.58$ & $3.33 \pm 0.58$ & $3.00 \pm 1.00$ \\
\hline & $70-79$ & Male & 23 & $3.70 \pm 1.36$ & $1.87 \pm 0.97$ & $1.91 \pm 1.12$ & $1.30 \pm 0.63$ & $2.87 \pm 0.76$ & $2.83 \pm 0.65$ & $2.00 \pm 1.04$ \\
\hline & & Female & 3 & $3.33 \pm 1.53$ & $1.00 \pm 0.00$ & $1.33 \pm 0.58$ & $1.00 \pm 0.00$ & $2.33 \pm 1.15$ & $2.67 \pm 0.58$ & $1.67 \pm 1.15$ \\
\hline $\mathrm{Cl}$ & & & & \multicolumn{7}{|c|}{ COOP/WONCA chart } \\
\hline Group & Age (y) & Sex & $\mathrm{n}$ & $\begin{array}{l}\text { Physical } \\
\text { fitness }\end{array}$ & Feelings & $\begin{array}{c}\text { Daily } \\
\text { activities }\end{array}$ & $\begin{array}{c}\text { Social } \\
\text { activities }\end{array}$ & $\begin{array}{l}\text { Change of } \\
\text { health }\end{array}$ & $\begin{array}{l}\text { Overall } \\
\text { health }\end{array}$ & Pain \\
\hline \multirow[t]{6}{*}{ Healthy subjects } & $50-59$ & Male & 14 & $2.07 \pm 1.27$ & $1.21 \pm 0.85$ & $1.07 \pm 0.27$ & $1.00 \pm 0.00$ & $2.93 \pm 0.27$ & $2.43 \pm 0.94$ & $1.79 \pm 1.12$ \\
\hline & & Female & 51 & $2.51 \pm 0.18$ & $1.31 \pm 0.47$ & $1.20 \pm 0.49$ & $1.14 \pm 0.53$ & $3.02 \pm 0.14$ & $2.65 \pm 1.00$ & $1.78 \pm 1.06$ \\
\hline & $60-69$ & Male & 32 & $2.03 \pm 1.12 \#$ & $1.31 \pm 0.69$ & $1.13 \pm$ & .39 & $2.94 \pm 0.50$ & $2.38 \pm 0.91$ & $1.41 \pm 0.76$ \\
\hline & & Female & 32 & $3.00 \pm 1.37$ & $1.44 \pm 0.50$ & $1.31 \pm 0.64$ & $1.19 \pm 0.40$ & $3.00 \pm 0.51$ & $2.88 \pm 1.13$ & $1.97 \pm 1.06$ \\
\hline & $70-79$ & Male & 32 & $3.03 \pm 1.12$ & $1.16 \pm 0.45$ & $1.03 \pm 0.18$ & $1.06 \pm 0.25$ & $2.94 \pm 0.44$ & $2.88 \pm 0.83$ & $1.59 \pm 0.84 \#$ \\
\hline & & Female & 38 & $3.74 \pm 1.20$ & $1.24 \pm 0.43$ & $1.13 \pm 0.34$ & $1.13 \pm 0.34$ & $3.05 \pm 0.46$ & $3.32 \pm 0.99$ & $2.39 \pm 1.10$ \\
\hline \multirow{6}{*}{$\begin{array}{l}\text { Patients with } \\
\text { moderate COPD }\end{array}$} & $50-59$ & Male & 16 & $3.56 \pm 0.81^{* *}$ & $1.75 \pm 0.86$ & $2.19 \pm 0.91$ & $1.62 \pm 0.72$ & $2.56 \pm 1.09$ & $3.50 \pm 0.63^{*}$ & $1.94 \pm 0.93$ \\
\hline & & Female & 18 & $3.44 \pm 0.31$ & $2.00 \pm 0.97^{* *}$ & $2.33 \pm 0.84^{* *}$ & $1.83 \pm 0.71^{* *}$ & $2.61 \pm 0.98$ & $3.44 \pm 0.92$ & $2.50 \pm 1.04$ \\
\hline & $60-69$ & Male & 21 & $3.52 \pm 0.87^{* *}$ & $1.90 \pm 0.83$ & $1.67 \pm 0.66$ & $1.76 \pm 0.83$ & $2.71 \pm 1.10$ & $3.19 \pm 1.08^{*}$ & $2.33 \pm 0.91^{*}$ \\
\hline & & Female & 17 & $3.41 \pm 0.62$ & $2.35 \pm 0.49^{* *}$ & $2.29 \pm 0.69^{* *}$ & $2.24 \pm 0.66$ & $3.18 \pm 0.95$ & $3.35 \pm 0.61$ & $2.35 \pm 0.70$ \\
\hline & $70-79$ & Male & 21 & $3.71 \pm 0.78$ & $2.14 \pm 0.73^{* *}$ & $2.24 \pm 0.89 * *$ & $2.00 \pm 0.89^{*}$ & $3.19 \pm 1.40$ & $3.57 \pm 0.75$ & $2.10 \pm 1.04$ \\
\hline & & Female & 9 & $3.44 \pm 0.88$ & $2.33 \pm 1.00^{* *}$ & $2.33 \pm 1.00^{* *}$ & $2.22 \pm 0.83^{* *}$ & $2.78 \pm 1.39$ & $3.44 \pm 0.73$ & $2.78 \pm 0.83$ \\
\hline \multirow{6}{*}{$\begin{array}{l}\text { Patients with } \\
\text { severe COPD }\end{array}$} & $50-59$ & Male & 16 & $4.06 \pm 1.12^{* *}$ & $2.13 \pm 1.09$ & $2.69 \pm 1.25^{*}$ & $2.44 \pm 1.36^{* *}$ & $3.25 \pm 1.00$ & $3.56 \pm 0.96^{*}$ & $2.50 \pm 1.21$ \\
\hline & & Female & 4 & $4.25 \pm 0.65$ & $3.25 \pm 0.50^{* *}$ & $4.00 \pm 0.00^{* *}$ & $4.00 \pm 0.00^{* *}$ & $4.00 \pm 0.00^{* *}$ & $4.00 \pm 0.00$ & $3.75 \pm 0.50^{*}$ \\
\hline & $60-69$ & Male & 29 & $4.00 \pm 1.10^{* *}$ & $2.41 \pm 1.12^{* *}$ & $2.90 \pm 1.21^{* *}$ & $2.79 \pm 1.18^{* *}$ & $3.14 \pm 1.16$ & $3.90 \pm 0.77^{* *}$ & $3.03 \pm 1.12^{* *}$ \\
\hline & & Female & 9 & $4.33 \pm 0.71^{*}$ & $2.67 \pm 1.32^{* *}$ & $3.00 \pm 1.41^{* *}$ & $1.89 \pm 1.05^{* *}$ & $3.67 \pm 0.71$ & $4.22 \pm 0.44^{* *}$ & $3.22 \pm 1.20^{*}$ \\
\hline & $70-79$ & Male & 27 & $4.26 \pm 0.94^{* *}$ & $2.52 \pm 1.25^{* *}$ & $3.19 \pm 1.14^{* *}$ & $2.78 \pm 1.34^{* *}$ & $3.30 \pm 1.38$ & $4.04 \pm 0.81^{* *}$ & $2.78 \pm 1.09^{* * \#}$ \\
\hline & & Female & 14 & $4.50 \pm 0.52$ & $3.14 \pm 1.10^{* *}$ & $3.93 \pm 1.14^{* *}$ & $3.36 \pm 1.35^{* *}$ & $3.64 \pm 1.01$ & $3.86 \pm 0.77$ & $3.86 \pm 0.86^{* *}$ \\
\hline
\end{tabular}


on sex and age, the correlation coefficient between patients and their doctors was $>0.527$ in the Japanese group, except for the "Pain" chart, and $>0.826$ in the Chinese group for all of the items.

The Japanese patients with COPD gave higher scores on the "Pain" item than the doctor's evaluation did, indicating that the doctor had underestimated the pain the patients felt. This discrepancy may be due in part to Japanese characteristics such as stoicism. The significant correlations of the COOP/WONCA chart items with the number of respiratory symptoms associated with COPD and with COPD status support the external validity of the charts. However, there were two aspects of the COOP/ WONCA charts that differed between the Japanese and Chinese subjects. One was that there was no significant correlation between "Pain" and the number of respiratory symptoms of COPD in the Japanese group; the other was that all of the items, except "Change in health", showed higher correlation with $\mathrm{BI}$ in the Chinese group than in the Japanese group. Pain control may have been more complete in Japanese patients with COPD than in Chinese patients. The reasons for the low correlation between $\mathrm{BI}$ and COOP/WONCA charts in the Japanese population are not clear. Cigarette type, smoking habits, and the tobacco smoking environment surrounding the patient may have contributed to these differences in the Japanese and Chinese groups.

To clarify the determinants of the COOP/WONCA chart items, we performed stepwise multiple regressions, adjusting by nationality, age, sex, COPD status, number of respiratory symptoms, and heating sources. The COPD status, the number of respiratory symptoms, or both were predictive variables for all of the items except "Change of health". This result suggests that the health status measured by the COOP/WONCA charts reflected the levels and conditions of COPD patients. In addition, those scores on all items except "Feelings" and "Overall health" could be compared between the Japanese and Chinese populations according to the result from stepwise multiple regression analyses. Although nationality was a predictive variable for "Feelings" and "Overall health", the scores for "Feelings" among healthy subjects were better in the Chinese group than in the Japanese group, whereas for the COPD patients, the "Overall health" score was better in the Japanese group than in the Chinese group. The social environment surrounding the patients, lifestyle, cultural and religious background, and medical treatments may influence "Feelings" and "Overall health" in complicated ways. It is necessary to analyze this point in more detail. The reliability and validity of the English version of the COOP/WONCA charts has been tested with COPD patients. Stavem and Jodalen [19] observed high correlation between items on the COOP/WONCA charts and the EuroQol 5-
Dimension (EQ-5D) test in 59 male and female outpatients with COPD (average age 57 years old). The authors suggested that the reliability of the COOP/WONCA items was acceptable for use at the group level, but lower than current recommendations for use in individual patients. In contrast, Eaton et al. [17] found that the Dartmouth COOP charts were reliable, valid, and responsive compared with the SF-36, Chronic Respiratory Questionnaire (CRQ), and Hospital Anxiety and Depression (HAD) questionnaires in a comparative study of oxygen therapy for patients with COPD, who were on average 68.3 years old. The authors showed that these charts are a simple, reliable health-related quality-of-life tool that was valid and responsive in their population of COPD patients and may have a valuable role in routine clinical practice. Our results also suggested that the Japanese and Chinese versions of the COOP/WONCA charts provide good reliability and validity for measuring health status and for comparing healthy subjects and patients with COPD in Japanese and Chinese populations.

\section{Comparison of health status in Japanese and Chinese patients with COPD by using COOP/WONCA charts}

1. In our Japanese subjects, patients with COPD showed almost the same health status as healthy subjects of the same age, when stratified by sex, age, and COPD status (Table 6). However, although the healthy Chinese subjects had clearly higher health status than the Japanese subjects, the health status declined in proportion to GOLD stage in patients with COPD. In particular, for Chinese subjects, the physical score and daily and social activity scores were worse in the patients with moderate COPD than in the healthy subjects, and the pain and psychological health status worsened further in the patients with severe COPD. The poor "Overall health" in the patients with severe COPD may reflect the strong deterioration of physical and social activity and psychological performance.

Few studies have used the COOP/WONCA charts to evaluate chronic disease and health status in COPD patients and have compared the results between countries. There is only one report that we know of that compared the results of a factor analysis of COOP/WONCA charts at primary care clinics in four countries and showed the average scores on each item and the 95\% confidence interval [20]. The authors suggested that the COOP/WONCA system was suitable for general use in primary care internationally.

The present study clarified that although healthy Chinese 50- to 79-year-olds have higher health status than corresponding Japanese people, the health status of 
Chinese patients with COPD decreases as symptoms get worse. Because a high positive correlation was observed between indoor use of smoky fuels and "Daily activity" and "Social activity" scores in the Chinese group, use of these fuels may be one of the precipitating factors of COPD in the Chinese population. More than $20 \%$ of Chinese males and females in this study were using coal or biomass indoors; indoor use of smoky fuels was associated with worse respiratory symptoms, which restrained physical and social activity. Diette et al. [27] reviewed the relation of biomass combustion exposure in an indoor environment and pulmonary obstructive disease, and found that combustion of biomass or coal indoors can lead to a fall in pulmonary function and aggravation of COPD. Therefore, the use of indoor heating and cooking equipment that does not produce smoke and the avoidance of cigarette smoking may improve physical and social activity and psychological levels as well as medical treatment, including pain control. Future studies should analyze risk factors related to health status in patients with COPD in the Chinese population. Aging and air pollution are increasing rapidly in Asia, which will likely increase the rate of COPD disease and related mortality. Immediate action to reduce risk factors leading to COPD may be required for improving the health economic and social burdens caused by the disability-adjusted life years lost due to COPD.

\section{Conclusions}

The Japanese and Chinese versions of the COOP/WONCA charts showed good reliability and validity for measuring health status and for comparing healthy subjects and patients with COPD in Japanese and Chinese populations.

The physical, psychosocial activities, and pain scores increased significantly as COPD status worsened in Chinese subjects, whereas these scores were not affected by sex, age, or COPD status for Japanese subjects. Brinkman index and indoor use of smoky fuel affected the COOP/WONCA scores in Chinese patients but not in Japanese patients. These results suggest that countermeasures against insufficient health care and smoky environments may improve the health status of Chinese patients with COPD.

\section{Additional files}

Additional file 1: SF-36v2 questionnaire for health survey.

Additional file 2: The Dartmouth COOP Functional Health Assessment Charts/WONCA (The COOP/WONCA Charts).

\section{Abbreviations}

COPD: Chronic obstructive pulmonary disease; WONCA: World Organization of National Colleges, Academies and Academic Associations of General Practitioners/Family Physicians; SF-36: SF-36V2 ${ }^{\text {TM }}$; GOLD: Global initiative for chronic obstructive lung disease; BI: Brinkman index; ICC: Intraclass correlation coefficient; CRQ: Chronic Respiratory Questionnaire; HAD questionnaire: Hospital Anxiety and Depression questionnaire.

\section{Competing interests}

Authors have no competing interests to declare.

\section{Authors' contributions}

MY was a graduate student at Kurume University and was involved in the literature search, data collection, and data editing. She took the lead in developing this manuscript. MN supervised MY; was involved in data editing, analysis and interpretation; provided discussion and advice; and helped to prepare the manuscript. H Obata was an advisor and was actively involved in data collection in Yamaguchi prefecture. HI and TK were also advisors and were actively involved in data collection in Nagasaki prefecture. QW was actively involved in data collection in the People's Republic of China. YH was an advisor and was involved in the literature search and data collection. $\mathrm{H}$ Omori was actively involved in data collection in Kumamoto prefecture. YI supervised MY and was involved in the literature search; data collection, editing, analysis, and interpretation; provided discussion and advice; helped with manuscript preparation; and participated in the development of the study proposal. She also supervised all aspects of this study. All authors read and approved the final manuscript

\section{Acknowledgments}

The authors would like to express their deep gratitude to all the doctors who provided the valuable data used in this study, which was conducted at the following institutions in Japan and the People's Republic of China. Dr. Hiroshi Fujita, Chairperson of Shimonoseki COPD study group, Shimonoseki, Japan; Japanese Red Cross Society Kumamoto Health Management Center, Kumamoto, Japan; Prof. Bei He, Peking University Third Hospital, Beijing, China; Prof. Wang Ping, The 306th Hospital of People's Liberation Army, Beijing, China; Dr. Qiu Jun, Neimenggu Xinganmeng People Hospital, Ulanhot, China; and Prof. Qianhua Zhao, Huashan Hospital Affiliated to Fudan University, Shanghai, China.

This study was supported in part by Grants-in-Aid for Scientific Research (B) 20406001 (YI) and 23406001 (Yl and MN), and a "MEXT-Supported Program for the Strategic Research Foundation at Private Universities" from the Ministry of Education, Culture, Sports, Science and Technology, "MEXT" in Japan (YI and MN). We also extend our appreciation to Dr. Go Hasegawa, Ms. Tomoe Terasaki at Kurume University, and Dr. XiuLing Li at Peking University for providing helpful support for this study.

\section{Author details}

'Department of Public Health, School of Medicine, Kurume University, Kurume, Fukuoka 830-0011, Japan. ${ }^{2}$ Yamaguchi-Ken Saiseikai Shimonoseki General Hospital, Yamaguchi 759-6603, Japan. ${ }^{3}$ Nagasaki Goto Chuoh Hospital, Nagasaki 853-0031, Japan. ${ }^{4}$ Institute of Population and Labor Economics, Chinese Academy of Social Sciences, Beijing 100732, China. ${ }^{5}$ Department of Public Health, Faculty of Life Sciences, Kumamoto University, Kumamoto 860-8556, Japan.

Received: 12 January 2013 Accepted: 12 August 2013

Published: 15 August 2013

\section{References}

1. Snider GL: Chronic obstructive pulmonary disease: risk factors, pathophysiology and pathogenesis. Annu Rev Med 1989, 40:411-429.

2. Maciewicz RA, Warburton D, Rennard SI: Can increased understanding of the role of lung development and aging drive new advances in chronic obstructive pulmonary disease? Proc Am Thorac Soc 2009, 6:614-617.

3. World Health Organization: World Health Report 2000, Geneva. http://www. who.int/whr/2000/en/whro0_en.pdf.

4. Anthonisen NR, Connett JE, Murray RP: Smoking and lung function of Lung Health Study participants after 11 years. Am J Respir Crit Care Med 2002, 166:675-679.

5. Eisner MD, Anthonisen N, Coultas D, Kuenzli N, Perez-Padilla R, Postma D, Romieu I, Silverman EK, Balmes JR, Committee on Nonsmoking COPD, Environmental and Occupational Health Assembly: An official American Thoracic Society public policy statement: Novel risk factors and the global burden of chronic obstructive pulmonary disease. Am J Respir Crit Care Med 2010, 182:693-718.

6. World Health Organization: WHO report in the global tobacco epidemic. Warning about the dangers of tobacco 2011, Japan. http://www.who.int/ tobacco/surveillance/policy/country_profile/jpn.pdf. 
7. Health, Labour and Welfare Statistics Association: Journal of Health and Welfare Statistics 2012, 59. Japan.

8. Giovino GA, Mirza SA, Samet JM, Gupta PC, Jarvis MJ, Bhala N, Peto R, Zatonski W, Hsia J, Morton J, Palipudi KM, Asma S, GATS Collaborative Group: Tobacco use in 3 billion individuals from 16 countries: an analysis of nationally representative cross-sectional household surveys. Lancet 2012, 380:668-679.

9. Fukuchi Y, Nishimura M, Ichinose M, Adachi M, Nagai A, Kuriyama T, Takahashi K, Nishimura K, Ishioka S, Aizawa H, Zaher C: COPD in Japan: the Nippon COPD epidemiology study. Respirology 2004, 9:458-465.

10. Zhong N, Wang C, Yao W, Chen P, Kang J, Huang S, Chen B, Wang C, Ni D, Zhou Y, Liu S, Wang X, Wang D, Lu J, Zheng J, Ran P: Prevalence of chronic obstructive pulmonary disease in China: a large, populationbased survey. Am J Respir Crit Care Med 2007, 176:753-760.

11. Buist AS, McBurnie MA, Vollmer WM, Gillespie S, Burney P, Mannino DM, Menezes AM, Sullivan SD, Lee TA, Weiss KB, Jensen RL, Marks GB, Gulsvik A, Nizankowska-Mogilnicka E, BOLD Collaborative Research Group: International variation in the prevalence of COPD (the BOLD Study): a population-based prevalence study. Lancet 2007, 370:741-750.

12. National Heart, Lung and Blood Institute: Morbidity and mortality chart book on cardiovascular, lung and blood diseases. Bethesda, MD; 2012. http://www. nhlbi.nih.gov/resources/docs/2012_ChartBook.pdf.

13. Mathers $C D$, Loncar D: Projections of global mortality and burden of disease from 2002 to 2030. PLoS Med 2006, 3:e442.

14. Sethi S, Murphy TF: Infection in the pathogenesis and course of chronic obstructive pulmonary disease. N Engl J Med 2008, 359:2355-2365.

15. Van Weel C: Functional status in primary care: COOP/WONCA charts. Disabil Rehabil 1993, 15:96-101.

16. Lam CL, van Weel C, Lauder IJ: Can the Dartmouth COOP/WONCA charts be used to assess the functional status of Chinese patients? Fam Pract 1994, 11:85-94.

17. Eaton T, Young P, Fergusson W, Garrett JE, Kolbe J: The Dartmouth COOP Charts: a simple, reliable, valid and responsive quality of life tool for chronic obstructive pulmonary disease. Qual Life Res 2005, 14:575-585.

18. Lam CL, Lauder IJ: The impact of chronic diseases on the health-related quality of life (HRQOL) of Chinese patients in primary care. Fam Pract 2000, 17:159-166.

19. Stavem K, Jodalen H: Reliability and validity of the COOP/WONCA health status measure in patients with chronic obstructive pulmonary disease. Qual Life Res 2002, 11:527-533.

20. Westbury RC, Rogers TB, Briggs TE, Allison DJ, Gérvas J, Shigemoto H, Elford W: A multinational study of the factorial structure and other characteristics of the Dartmouth COOP Functional Health Assessment Charts/WONCA. Fam Pract 1997, 14:478-485.

21. Global Initiative for Chronic Obstructive Lung Disease (GOLD): Global Strategy for the Diagnosis, Management and Prevention of COPD. 2011. http://www. goldcopd.org/uploads/users/files/GOLD_Report_2011_Feb21.pdf.

22. Fukuhara S, Suzukamo Y: Manual of SF-36v2 Japanese version. Kyoto: Institute for Health outcome \& Process Evaluation Research; 2004.

23. Murphy DD, Lam CL: Feasibility and acceptability of the COOP/WONCA charts for identification of functional limitations in rural patients of the People's Republic of China. Int J Rehabil Res 2001, 24:207-219.

24. Hayasaka Y, Hayasaka S: Functional health status of patients at initial visit in primary eye clinic assessed using the Japanese versions of the COOP charts. Ann Ophthalmol (Skokie, III) 2006, 38:53-60.

25. Chen $X$, Sekine M, Hamanishi $S$, Wang H, Gaina A, Yamagami T, Kagamimori S: Lifestyles and health-related quality of life in Japanese school children: a cross-sectional study. Prev Med 2005, 40:668-678.

26. Chen X, Sekine M, Hamanishi S, Yamagami T, Kagamimori S: Associations of lifestyle factors with quality of life (QOL) in Japanese children: a 3-year followup of the Toyama Birth Cohort Study. Child Care Health Dev 2005, 31:433-439.

27. Diette GB, Accinelli RA, Balmes JR, Buist AS, Checkley W, Garbe P, Hansel NN, Kapil V, Gordon S, Lagat DK, Yip F, Mortimer K, Perez-Padilla R, Roth C, Schwaninger JM, Punturieri A, Kiley J: Obstructive lung disease and exposure to burning biomass fuel in the indoor environment. Glob Heart 2012, 7:265-270

doi:10.1186/1471-2458-13-754

Cite this article as: Yamaguchi et al: Application of the COOP/WONCA charts to aged patients with chronic obstructive pulmonary disease: a comparison between Japanese and Chinese populations. BMC Public Health 2013 13:754

\section{Submit your next manuscript to BioMed Central and take full advantage of:}

- Convenient online submission

- Thorough peer review

- No space constraints or color figure charges

- Immediate publication on acceptance

- Inclusion in PubMed, CAS, Scopus and Google Scholar

- Research which is freely available for redistribution 